\title{
ENRAIZAMENTO DE ESTACAS DE Passiflora nitida SUBMETIDAS A DIFERENTES CONCENTRAÇÕES DE ÁCIDO INDOLBUTÍRICO (AIB) ${ }^{1}$
}

\author{
RAFAEL ROVERI SABIÃO², ADRIANA DE CASTRO CORREIA DA SILVA ${ }^{3}$, \\ ANTONIO BALDO GERALDO MARTINS ${ }^{4}$, ELIANE RIBEIRO CARDOSO ${ }^{5}$
}

RESUMO - O presente trabalho objetivou avaliar o enraizamento de estacas de $P$. nitida, utilizando dois tipos de estacas (com 1 e 2 gemas) e 4 doses de ácido indolbutírico (AIB) $\left(0 ; 1.000 ; 3.000\right.$ e $\left.5.000 \mathrm{mgL}^{-1}\right)$ com imersão lenta (5 segundos), com a finalidade de utilizá-las como porta-enxerto do maracujazeiro-azedo. O delineamento experimental utilizado foi inteiramente casualizado, em esquema fatorial $4 \times 2$ (concentrações de AIB x número de gemas na estaca), com quatro repetições de 10 estacas, totalizando 320 estacas. As estacas foram dispostas em bandejas plásticas, contendo vermiculita expandida de textura média, e mantidas sob sistema de nebulização intermitente, por 25 dias. As doses de AIB testadas influenciaram na sobrevivência, enraizamento das estacas e número e comprimento de raízes; e o número de gemas não influenciou no enraizamento de estacas.

Termos para indexação: propagação, estaquia, ácido indolbutírico, Passifloraceae, maracujá-suspiro.

\section{CUTTING ROOTING OF Passiflora nitida SUBMITTED TO DIFFERENT CONCENTRATIONS OF indol butyric acid (IBA)}

\begin{abstract}
This study aimed to evaluate the rooting of $P$. nitida, using two types of cuttings ( 1 and 2 buds) and four concentrations of $\operatorname{IBA}(0,1000,3000$ and $5000 \mathrm{mg} / \mathrm{L})$ with slow immersion (5 seconds) in order to use them as a passion fruit rootstock. The experimental design was completely randomized in a $4 \times 2$ factorial arrangement (IBA concentrations x number of buds on cuttings), four replications of 10 cuttings, total of 320 cuttings. The cuttings were placed in plastic trays containing expanded vermiculite of medium texture, and kept under intermittent nebulization system for 25 days. The IBA doses influenced the survival, the rooting of cuttings and the root number and length. The number of buds did not influence the cutting rooting. Index Terms: propagation, stem cuttings, IBA, Passifloraceae, wild passionfruit.
\end{abstract}

\section{INTRODUÇÃO}

O Brasil é o maior produtor mundial de maracujá, com aproximadamente 713 milhões de toneladas, numa área superior a 50 mil hectares, sendo o maracujá-azedo (Passiflora edulis Sims) predominante nos plantios do País (IBGE, 2011). Há um grande risco de redução drástica das áreas cultivadas, principalmente pela grande quantidade de patógenos, por isso é de extrema importância utilizar a resistência às doenças presentes em outras espécies nativas para diminuir os problemas encontrados na cultura (MELETTI et al., 2005).

O centro de origem do gênero Passiflora abrange a América tropical e subtropical, incluindo o Brasil, onde se estima encontrar até 150 espécies de maracujazeiros. Dentro destas espécies nativas pertencentes à família Passifloraceae, algumas apresentam características genéticas importantes, como resistência às doenças e pragas (JUNQUEIRA et al., 2005), que são as características de maior interesse atualmente, principalmente por estes problemas diminuírem a vida útil dos pomares, tornando a cultura nômade, por fugir de áreas endêmicas. Uma espécie que ganha destaque nesse cenário é a Passiflora nitida H.B.K. (maracujá-suspiro), que é bem conhecido e comercializado no Norte do País, com boas características físico-químicas, bom poten-

\footnotetext{
${ }^{1}$ Trabalho Sinfruit 165 - Simpósio Internacional de Fruticultura - Avanços na Fruticultura (17 a 21 Outubro)

${ }^{2}$ Eng. Agr., Mestrando em Agronomia (Programa Produção Vegetal), Departamento de Produção Vegetal, UNESP/FCAV, Câmpus de Jaboticabal. Via de acesso Prof. Paulo Donato Castellane, s/n, Cep: 14884-900. E-mail: rrsabiao@yahoo.com.br

${ }^{3}$ Eng. Agr., Doutoranda em Agronomia (Programa Produção Vegetal), Departamento de Produção Vegetal, UNESP/FCAV, Câmpus de Jaboticabal. Via de acesso Prof. Paulo Donato Castellane, s/n, Cep: 14884-900. E-mail: dri ubatuba@yahoo.com.br.

${ }^{4}$ Eng. Agr., Prof. Assist. Dr., Departamento de Produção Vegetal, UNESP/FCAV, Câmpus de Jaboticabal. Via de acesso Prof. Paulo Donato Castellane, s/n, Cep: 14884-900. E-mail: baldo@fcav.unesp.br

${ }^{5}$ Eng Agr. Dra. Pesquisadora do Viveiro Flora Brasil. Rodovia BR 050, km37/MG, Araguari-MG.

E-mail: florabrasil@viveiroflorabrasil.com.br
} 
cial mercadológico e possui resistência às principais doenças que afetam a cultura do maracujazeiro (JUNQUEIRA et al., 2010). Estudos utilizando o $P$. nitida como porta-exerto de maracujazeiro-azedo tiveram resultados significativos de resistência às doenças do sistema radicular em comparação com as plantas de maracujazeiro-azedo propagadas por sementes (JUNQUEIRA et al., 2006).

A espécie Passiflora nitida distribui-se na América do Sul, desde o Panamá até o Centro-Norte do Brasil, característica das capoeiras e vegetação baixa, sombreada e rasteira, não sendo encontradas dentro de matas fechadas nem a pleno sol. O fruto é ovoide, medindo cerca de $8,0 \mathrm{~cm}$ de altura e 3,0 a 7,0 $\mathrm{cm}$ de diâmetro, coloração da polpa é branca e a casca é amarelo-alaranjada, caracterizada pela consistência esponjosa, com $1,5 \mathrm{~cm}$ de espessura, que facilita a abertura do fruto com as mãos, facilitando também o consumo (MELETTI et al., 2010).

A produção de mudas seminíferas de $P$. nitida não é viável, pois a germinação não passa de $1 \%$, com sementes recém-colhidas, sendo que o armazenamento das sementes aumenta a taxa de germinação, entretanto não atinge níveis muito elevados. Por isso, recomenda-se a propagação através da estaquia, que também antecipa o florescimento e a frutificação (OLIVEIRA; RUGGIERO, 2005).

O objetivo do trabalho foi avaliar o enraizamento de estacas de $P$. nitida, utilizando dois tipos de estacas (com 1 e 2 gemas) e 4 doses de AIB $(0 ; 1.000$; 3.000 e $5.000 \mathrm{mg} / \mathrm{L}$ ), com a finalidade de utilizá-las como porta-enxerto do maracujazeiro-azedo.

\section{MATERIAL E MÉTODOS}

O experimento foi realizado na área experimental do Departamento de Produção Vegetal da Faculdade de Ciências Agrárias e Veterinárias, Universidade Estadual Paulista (FCAV/UNESP), Câmpus de Jaboticabal, com as coordenadas geográficas: $21^{\circ} 17^{\prime} 05^{\prime}$ 'S, $48^{\circ} 17^{\prime} 09^{\prime}$ W e altitude de aproximadamente $590 \mathrm{~m}$. O clima da região, segundo classificação de Köeppen, é do tipo Cwa, subtropical, relativamente seco no inverno, com chuvas no verão, apresentando temperatura média anual de $22^{\circ} \mathrm{C}$ e precipitação de $1.500 \mathrm{~mm}$.

O trabalho foi conduzido de abril a maio de 2011, em câmara de nebulização intermitente, sob telado (50\% de sombreamento). As matrizes de $P$. nitida pertencem ao Banco Ativo de Germoplasma do Departamento de Produção Vegetal e foram selecionadas em função da sanidade e vigor.

Estacas herbáceas foram retiradas da porção mediana de ramos em estádio de crescimento vege- tativo, com cerca de 10 e $12 \mathrm{~cm}$ de comprimento, com uma ou duas gemas e uma folha por gema, folha reduzida a metade na estaca com uma gema, corte em bisel na extremidade basal da estaca e corte perpendicular na extremidade apical. As estacas foram tratadas com o regulador AIB (ácido indolbutírico), nas concentrações de $0 ; 1.000 ; 3.000$ e $5.000 \mathrm{mgL}^{-1}$, por imersão da extremidade basal por 5 segundos.

As estacas foram dispostas em bandejas plásticas perfuradas contendo vermiculita de textura média, sob nebulização intermitente, com 15 segundos de molhamento e 45 segundos de intervalo. O tempo de permanência na câmara de nebulização foi de 25 dias, quando foram avaliadas a porcentagem de estacas enraizadas (estacas que emitiram pelo menos uma raiz), porcentagem de estacas sobreviventes (estacas que permaneceram verdes), número e comprimento de raízes por estaca, sendo contadas e mensuradas as raízes formadas nas estacas em cada repetição.

$\mathrm{O}$ delineamento experimental utilizado foi o inteiramente casualizado, com quatro repetições e 10 estacas por parcela, em esquema fatorial $4 \times 2$, sendo os fatores: concentrações de AIB $(0 ; 1.000 ; 3.000 \mathrm{e}$ $\left.5.000 \mathrm{mgL}^{-1}\right)$ e número de gemas deixadas na estaca (uma ou duas gemas). Os dados foram avaliados estatisticamente por análise de variância, utilizando o teste F, e as médias, comparadas entre si, pelo teste de Tukey, a 5\% de probabilidade. As variáveis porcentagem de enraizamento e porcentagem de sobrevivência foram transformadas por arco-seno $\sqrt{\frac{x}{100}}$

\section{RESULTADOS E DISCUSSÃO}

Os resultados de porcentagem de sobrevivência (Tabela 1) não apresentaram diferença significativa entre os tratamentos testados, sendo que se obteve a média de 99,7\% de sobrevivência, 25 dias após a estaquia, bem superior aos obtidos por Roncatto et al. (2008a) e Roncatto et al. (2008b), de 21,3\% e 27,2\%, respectivamente, para a mesma espécie, aos 60 dias.

A porcentagem de enraizamento atingiu a média de $86,3 \%$, tendo os melhores resultados para os tratamentos com doses $1.000 ; 3.000$ e $5.000 \mathrm{mgL}^{-}$ ${ }^{1}$, com $88,75 \%, 95 \%$ e $98,75 \%$ de enraizamento, respectivamente, diferindo significativamente da testemunha $\left(0 \mathrm{mgL}^{-1}\right)$, que atingiu o valor médio de $62,5 \%$ (Tabela 1). Os resultados diferem de valores encontrados em trabalhos com a mesma espécie, que apresentaram $40 \%$ de enraizamento, quando a estaquia foi realizado no mês de junho, utilizando a concentração de $500 \mathrm{mgL}^{-1}$ de AIB (RONCATTO et al., 2008b) e 40\% no mês de julho, sem utilizar 
regulador (RONCATTO et al., 2008a), indicando que o presente trabalho foi em melhor época para enraizamento e que o aumento das doses de AIB aumentam o enraizamento (Figura 1).

O número médio de raízes apresentou diferença estatística com a variação da concentração do regulador, diferindo de acordo com a concentração do regulador vegetal, com melhores resultados para doses de 3.000 e $5.000 \mathrm{mgL}^{-1}$ de AIB (21,9 e 24, 1 raízes, respectivamente), como pode ser visto na Figura 2, resultado também observado na propagação de aceroleira, na qual acréscimo na concentração de regulador aumentou o número e a massa seca de raízes por estaca, com maiores médias nas maiores concentrações (GONTIJO et al., 2003), concluindo que o uso do regulador vegetal influencia na divisão celular, proporcionando a melhor formação de raízes.

O número de gemas na estaca só apresentou diferença significativa quanto ao comprimento de raízes (Tabela 1), o que mostra ser possível realizar a estaquia de $P$. nitida deixando apenas uma gema por estaca. Braga et al. (2006) também não observaram diferença estatística na estaquia de três espécies de maracujazeiro, variando o número de gemas por estaca. O comprimento de raízes também diferiu significativamente com o aumento das doses de AIB, tendo melhores resultados para as doses superiores(Figura 2), mostrando que o aumento da concentração do regulador promove maior desenvolvimento do sistema radicular na espécie estudada.

TABELA 1 - Resultados médios obtidos de porcentagem de sobrevivência, enraizamento, número e comprimento médio de raízes de $P$. nitida em função do número de gemas e das doses de AIB. Jaboticabal, 2011

\begin{tabular}{|c|c|c|c|c|}
\hline Causas da Variação & $\begin{array}{l}\text { Porcentagem de } \\
\text { Sobrevivência }^{1}\end{array}$ & $\begin{array}{c}\text { Porcentagem de } \\
\text { Enraizamento }^{1}\end{array}$ & $\begin{array}{c}\text { Número Médio de } \\
\text { Raízes }\end{array}$ & $\begin{array}{c}\text { Comprimento Médio } \\
\text { de Raízes }\end{array}$ \\
\hline \multicolumn{5}{|l|}{ Número de Gemas } \\
\hline 1 gema & $88,85 \mathrm{a}$ & $70,54 \mathrm{a}$ & $15,37 \mathrm{a}$ & $2,09 \mathrm{~b}$ \\
\hline 2 gemas & $90,00 \mathrm{a}$ & $78,07 \mathrm{a}$ & $16,99 \mathrm{a}$ & $3,61 \mathrm{a}$ \\
\hline DMS (5\%) & 2,378 & 8,0013 & 3,0907 & 0,4013 \\
\hline \multicolumn{5}{|l|}{ Doses (mg/L) } \\
\hline 0 & $90,0 \mathrm{a}$ & $52,85 \mathrm{~b}$ & $3,70 \mathrm{c}$ & $1,76 \mathrm{c}$ \\
\hline 1000 & $90,0 \mathrm{a}$ & $74,59 \mathrm{a}$ & $15,01 \mathrm{~b}$ & $2,75 \mathrm{~b}$ \\
\hline 3000 & $90,0 \mathrm{a}$ & $82,07 \mathrm{a}$ & $21,88 \mathrm{a}$ & $3,19 \mathrm{ab}$ \\
\hline 5000 & $87,69 \mathrm{a}$ & 87,69 a & $24,14 \mathrm{a}$ & $3,70 \mathrm{a}$ \\
\hline DMS (5\%) & 4,495 & 15,1244 & 5,8421 & 0,7586 \\
\hline CV (\%) & 3,64 & 14,75 & 26,18 & 19,29 \\
\hline Média $^{2}$ & 99,7 & 86,3 & 16,2 & 2,9 \\
\hline
\end{tabular}

Médias seguidas pelas mesmas letras, na coluna, dentro de um mesmo fator de variação, não diferem entre si, pelo teste de Tukey.

${ }^{1}$ Para a análise estatística, os dados de porcentagem foram transformados em arco-seno $\sqrt{\mathbf{x}}$.

${ }^{2}$ Médias reais, sem transformação

$\sqrt{\mathbf{1 0 0}}$

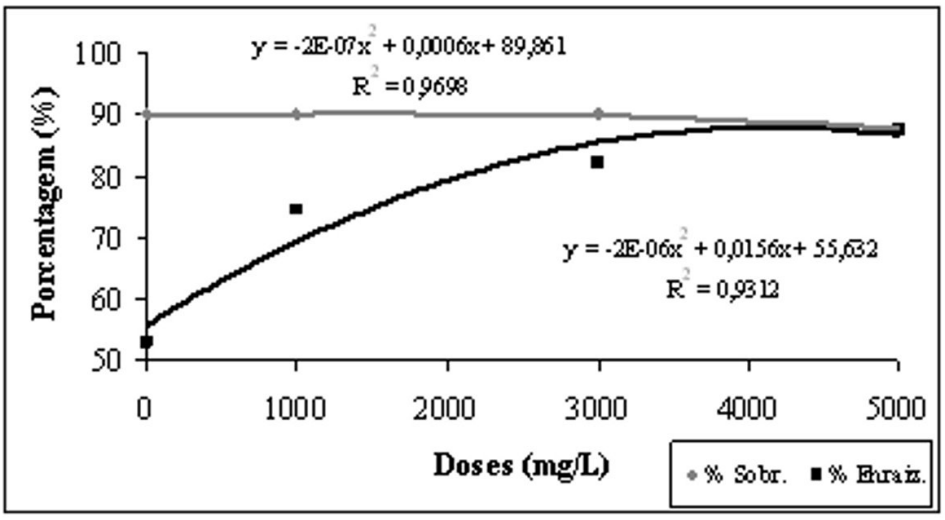

FIGURA 1 - Porcentagem de sobrevivência e enraizamento de estacas P. nitida, após 25 dias, tratadas com diferentes concentrações de AIB. Jaboticabal, 2011. 


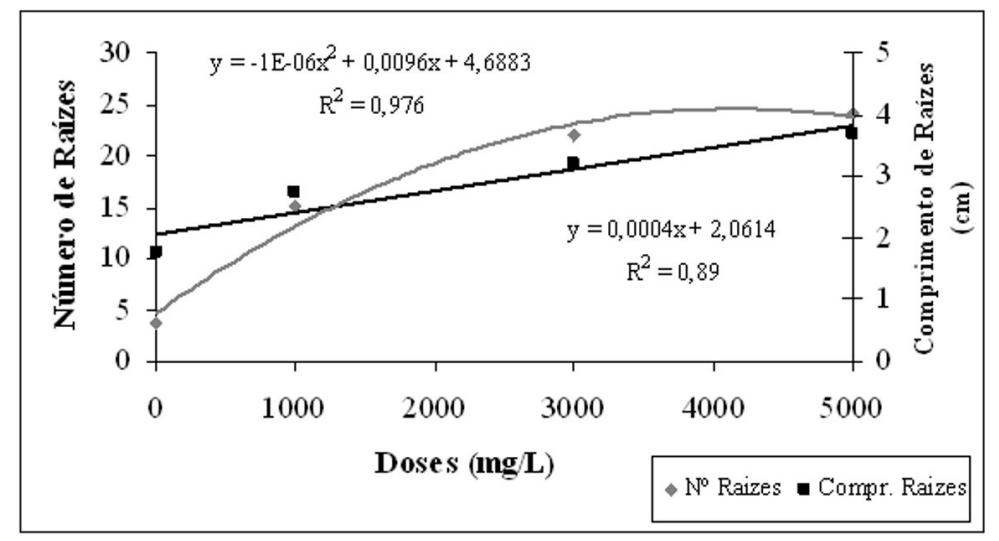

FIGURA 2 - Número e comprimento médio de raízes de estacas P. nitida, após 25 dias, tratadas com diferentes concentrações de AIB. Jaboticabal, 2011.

\section{CONCLUSÕES}

A espécie $P$. nítida pode ser propagada vegetativamente, utilizando-se de estacas de 1 gema, e a qualidade das mudas é influenciada pela concentração de AIB.

\section{REFERÊNCIAS}

BRAGA, M. F.; SANTOS, E. C.; JUNQUEIRA, N. T. V.; SOUSA, A. A. T. C.; FALEIRO, F. G.; REZENDE, L. N.; JUNQUEIRA, K. P. Enraizamento de estacas de três espécies silvestres de Passiflora. Revista Brasileira de Fruticultura, Jaboticabal, v.28, n.2, p.284-288, 2006.

GONTIJO, T. C. A.; RAMOS, J. D.; MENDONÇA, V.; PIO, R.; ARAÚJO NETO S. E.; CORRÊA, F. L. O. Enraizamento de diferentes tipos de estacas de aceroleira utilizando ácido indolbutírico. Revista Brasileira de Fruticultura, Jaboticabal, v.25, n.2, p.290-292, 2003.

IBGE. Banco de dados agregados: SIDRA. Disponível em: <http://www.sidra.ibge.gov.br>. Acesso em: 12 jul. 2011.

JUNQUEIRA, N. T. V.; BRAGA, M. F.; FALEIRO, F. G.; PEIXOTO, J. R.; BERNACCI, L. C. Potencial de espécies silvestres de maracujazeiro como fonte de resistência a doenças. In: FALEIRO, F. G.; JUNQUEIRA, N. T. V.; BRAGA, M. F. Maracujá: germoplasma e melhoramento genético. PlanaltinaDF: Embrapa Cerrados, 2005. p.81-108.
JUNQUEIRA, N. T. V.; LAGE, D. A. C.; BRAGA, M. F.; PEIXOTO, J. R.; BORGES, T. A.; ANDRADE, S. R. M. Reação a doenças e produtividade de um clone de maracujazeiro-azedo propagado por estaquia e enxertia em estacas herbáceas de Passiflora silvestre. Revista Brasileira de Fruticultura, Jaboticabal, v.28, n.1, p. 97-100, 2006.

JUNQUEIRA, N. T. V.; SANTOS, E. C.; JUNQUIERA, K. P.; FALEIRO, F. G.; BELLON, G.; BRAGA M. F. Características físico-químicas e produtividade de acessos de Passiflora nitida Kunth procedentes do centro-norte do Brasil. Revista Brasileira de Fruticultura, Jaboticabal, v.32, n.3, p.791-797, 2010.

MeletTI, L. M. M.; OliVEIRA, J. C. de; RUGGEIRO, C. Maracujá. Jaboticabal: Funep, 2010, 55p. (Série Frutas Nativas)

OLIVEIRA, J. C. de; RUGGIERO, C. Espécies de maracujá com potencial agronômico. In: FALEIRO, F. G.; JUNQUEIRA, N. T. V.; BRAGA, M. F. Maracujá: germoplasma e melhoramento genético. Planaltina-DF: Embrapa Cerrados, 2005. p. 41-51.

RONCATTO, G.; NOGUEIRA FILHO, G. C.; RUGGIERO, C.; OLIVEIRA, J. C.; MARTINS, A. B. G. Enraizamento de estacas de espécies de maracujazeiro (Passiflora spp.) no inverno e no verão. Revista Brasileira de Fruticultura, Jaboticabal, v.30, n.4, p.1089-1093, 2008a.

RONCATTO, G.; NOGUEIRA FILHO, G. C.; RUGGIERO, C.; OLIVEIRA, J. C.; MARTINS, A. B. G. Enraizamento de estacas herbáceas de diferentes espécies de maracujazeiro. Revista Brasileira de Fruticultura, Jaboticabal, v.30, n.4, p.1094-1099, 2008b. 